Kirill Sliozberg, Yauhen Aniskevich, Ugur Kayran, Justus Masa and Wolfgang Schuhmann*

\title{
CoFe-OH Double Hydroxide Films Electro- deposited on Ni-Foam as Electrocatalyst for the Oxygen Evolution Reaction
}

https://doi.org/10.1515/zpch-2019-1466

Received May 10, 2019; accepted December 17, 2019

Abstract: Cobalt-iron double hydroxide ( $\mathrm{CoFe}-\mathrm{OH}$ ) films were electrochemically deposited on 3D Ni foam electrodes for the oxygen evolution reaction (OER). The dependence of the OER activity on film composition and thickness was evaluated, which revealed an optimal Fe:Co ratio of about 1:2.33. The composition of the catalyst film was observed to vary with film thickness. The electrodeposition parameters were carefully controlled to yield microstructured Ni-foam decorated with $\mathrm{CoFe}-\mathrm{OH}$ films of controlled thickness and composition. The most active electrode exhibited an overpotential as low as $360 \mathrm{mV}$ OER at an industrial scale current density of $400 \mathrm{~mA} \mathrm{~cm}{ }^{-2}$ that remained stable for at least $320 \mathrm{~h}$. This work contributes towards the fabrication of practical electrodes with the focus on the development of stable electrodes for electrocatalytic oxygen evolution at high current densities.

Keywords: double hydroxide; electrocatalysis; electrodeposition; long-term stability; Ni foam; oxygen evolution reaction.

\section{Introduction}

The finiteness of fossil fuels and the negative consequences of their use on the environment and global climate calls for urgent search for alternative energy sources and technologies for posterity. One of the most appealing possible solutions is seen in the hydrogen economy [1, 2]. Efficient water electrolysis using

\footnotetext{
*Corresponding author: Wolfgang Schuhmann, Analytical Chemistry - Center for Electrochemical Sciences (CES), Faculty of Chemistry and Biochemistry, Ruhr University Bochum, Universitätsstrasse 150, D-44780 Bochum, Germany, e-mail: wolfgang.schuhmann@rub.de
}

Kirill Sliozberg, Yauhen Aniskevich, Ugur Kayran and Justus Masa: Analytical Chemistry Center for Electrochemical Sciences (CES), Faculty of Chemistry and Biochemistry, Ruhr University Bochum, Universitätsstrasse 150, D-44780 Bochum, Germany 
excess energy from renewable energy sources such as solar and wind to produce $\mathrm{H}_{2}$ as a clean energy carrier has the potential to profoundly contribute to the global drive for the transition from unsustainable and environmentally nonfriendly energy systems toward ecofriendly and sustainable energy systems. The efficiency and cost-effectiveness of water electrolysis for hydrogen production remains challenging and economically non-competitive, for example, compared to hydrogen production from fossil resources by steam reforming. Whereas the hydrogen evolution reaction (HER), a two-electron transfer process, is kinetically fast and mechanistically simple, the oxygen evolution reaction (OER) has a comparatively more complex mechanism, which includes four electron-proton transfer steps [3], manifesting into large overpotential for the OER. To make hydrogen produced from water splitting affordable, it is imperative to reduce the cost of water electrolysis, which can be achieved through the design of low-cost but highly efficient electrocatalysts for both the HER and the OER. The activity of electrocatalysts is however not the only crucial factor that influences the efficiency of water electrolysis. Further to identification of effective electrocatalysts, several electrode engineering aspects, such as enhancing the active surface area of the electrodes and the long-term stability, have to be considered for holistic enhancement of electrolytic efficiency. Porous conductive substrates provide the possibility to increase the surface area of electrodes and simultaneously solve issues related to gas evolution in an electrolyzer. Nickel foam is an attractive electrode material for alkaline water electrolysis due to its high corrosion resistance at anodic potentials and its relatively low cost. Ni-foam by itself is, however, not sufficiently active for OER electrocatalysis and hence has to be modified with catalytically active materials, for example, by dip- [4] or spray-coating [5] of catalyst suspensions with or without a binder, gas phase deposition by CVD [6] or PVD [7], as well as chemical [8] and electrochemical deposition [9], among others. Electrochemical deposition strategies are particularly attractive due to their simplicity, scalability, homogeneous substrate coverage and absence of passivating binders. Importantly, each deposited catalyst particle is electrically connected to the underlying electrode surface. One class of active OER catalysts which can be electrochemically deposited are transition metal hydroxides [10, 11], which makes them attractive for fabrication of porous electrodes. Co- [12, 13], Ni- [14], and Fe-based (oxy)hydroxides [15] are attractive oxygen evolution electrocatalysts because of their low cost and stability in alkaline solutions [16]. The OER activity of $\mathrm{Ni} / \mathrm{Fe}-[17], \mathrm{Co} / \mathrm{Al}-[18]$, and $\mathrm{Co} / \mathrm{Fe}-[19,20]$ double (oxy)hydroxides is substantially enhanced as compared to the respective single (oxy)hydroxides. Studies on electrochemically deposited $\mathrm{Fe}-\mathrm{Co}$ and $\mathrm{Al}-\mathrm{Co}$ layer double hydroxides (LDH) have revealed that the presence of Fe significantly promotes the activity of Cobased LDH OER-catalysts [18]. Burke et al. investigated the OER activity of Co-Fe 
double hydroxides prepared by galvanostatic electrodeposition from Co(II)- and $\mathrm{Fe}(\mathrm{II})$-chloride containing solutions [19]. After electrodeposition and electrooxidation, $\mathrm{Fe}_{\mathrm{x}} \mathrm{Co}_{1-\mathrm{x}} \mathrm{OOH}$ films were obtained. The highest catalytic activity, that is, the highest turnover frequency (TOF) was observed for $\mathrm{x} \approx 0.5$. With increasing $\mathrm{Fe}$ content $(\mathrm{x}>0.54)$, the stability of the hydroxide in $\mathrm{KOH}$ decreases due to dissolution during anodic polarization. In addition, electrocatalytic performance diminishes for Fe-rich films because of their poor electrical conductivity [21]. Anodically deposited $\mathrm{CoFeO}_{\mathrm{x}}$ films showed four types of loading-activity dependences due to film nucleation and growth as well as resistance of the films [22]. The Co:Fe ratio in the thin catalyst films prepared by electrodeposition strongly depends on the deposition conditions and is difficult to control due to dissimilar deposition kinetics of the individual ions. It was shown for $\mathrm{Co} / \mathrm{Al}$ and $\mathrm{Co} / \mathrm{Fe}$-based LDHs prepared by co-precipitation that $\mathrm{Al}^{3+}$ suppressed OER activity, whereas $\mathrm{Fe}^{3+}$ generally enhanced the activity with the optimum content of Fe being about 35 at\%. [23]

In this work, the outstanding electrocatalytic properties of Co-Fe double hydroxides for the OER together with the attractive properties of Ni foam as 3D catalyst support, were exploited to develop a high-performance $\mathrm{CoFe}-\mathrm{OH} / \mathrm{Ni}$-foam anode for the OER with high activity and long-term stability at industrial scale current densities. The nickel foam substrate itself certainly has an influence on the properties of the resulting catalysts arising from catalyst-support interactions. Therefore, in order to decouple substrate effects from the influence of the deposition method as well as the $\mathrm{FeCo}-\mathrm{OH}$ precursor composition on the electrocatalytic properties of the formed films, including the film thickness, composition and morphology, the activity of the electrodeposited films was first separately investigated on a rotating-disk electrode made of bulk nickel. The optimized catalyst deposition procedure was subsequently adapted for electrochemical modification of pre-structured Ni foam. The long-term stability of the resulting electrode was evaluated at an industrial scale current density of $400 \mathrm{~mA} \mathrm{~cm}^{-2}$ during which the potential remained below $1.6 \mathrm{~V}$ vs. RHE for a test period of $320 \mathrm{~h}$. Stability tests at such high current densities and durations are rarely reported, which underscores the contribution of this work towards the development of practical low-cost and efficient electrodes for the OER.

\section{Experimental}

\subsection{Materials}

All reagents were of analytical grade and used as received. Cobalt(II) nitrate hexahydrate (99.999\%), iron(III) nitrate nonahydrate (99.95\%), $\mathrm{NiSO}_{4}$, and $\mathrm{NH}_{4} \mathrm{Cl}$ 
were from Sigma-Aldrich. $\mathrm{H}_{2} \mathrm{SO}_{4}(>95 \%)$ was from Fisher Chemical. Potassium nitrate (99\%) and potassium hydroxide (99.5\%) were purchased from Riedel-de Haën and Algin-Chemie, respectively. All solutions were prepared using ultrapure Milli-Q water (SG Water). Ni-foam with a bulk density of $0.45 \mathrm{~g} \mathrm{~cm}^{-3}$, porosity of $95 \%$ and purity $>95 \%$ was purchased from Shanghai Tankii Alloy Material.

\subsection{Electrode preparation}

Five millimetre Ni rotating disc electrodes (Ni-RDE) from Metrohm Autolab were polished on a polishing cloth to a mirror finish using alumina slurries of different grain sizes $(3,1,0.3$, and $0.05 \mu \mathrm{m}$, LECO). The polished Ni-RDEs were subsequently ultrasonicated in acetone, isopropanol, and deionized water for $5 \mathrm{~min}$ for complete removal of the alumina polishing residues. All electrodes were used for further modifications directly after cleaning.

\subsection{Modification of Ni-RDEs with $\mathrm{CoFe}-\mathrm{OH}$ catalyst films}

Modification of the Ni-RDEs with $\mathrm{CoFe}-\mathrm{OH}$ films was performed with an Autolab PGSTAT 30 potentiostat attached to an Autolab RDE-2 rotator (Metrohm). A standard 3-electrode coaxial cell configuration was used for electrodeposition. Pt-mesh was used as a counter electrode and $\mathrm{Ag} / \mathrm{AgCl} / 3 \mathrm{M} \mathrm{KCl} / 0.5 \mathrm{M} \mathrm{KNO}_{3}$ double junction electrode was used as reference (195 mV vs. NHE). Electrodeposition was carried out by applying a specific number of potential CV cycles between $0 \mathrm{mV}$ and $-800 \mathrm{mV}$ at $100 \mathrm{mV} / \mathrm{s}$ to the stationary electrode. The modified electrodes were rinsed with deionized water and immediately evaluated for OER activity.

\subsection{Electrochemical measurements on Ni-RDEs}

All RDE measurements were performed using a Gamry Reference 600 potentiostat (Gamry Instruments) attached to an Autolab RDE-2 rotator (Metrohm). The modified Ni-RDEs were tested in a three-electrode coaxial cell configuration with Pt mesh as counter electrode and a CHI152 alkaline mercury oxide reference electrode consisting of $\mathrm{Hg} / \mathrm{HgO} / 0.1 \mathrm{M} \mathrm{KOH} \mathrm{(157} \mathrm{mV} \mathrm{vs.} \mathrm{NHE).} \mathrm{The} \mathrm{electrolyte} \mathrm{was}$ $0.1 \mathrm{M} \mathrm{KOH}$ saturated with $\mathrm{O}_{2}$. The concentration of the electrolyte was controlled by titration with potassium hydrogen phthalate (KHP) as a primary standard. The $\mathrm{pH}$ value of the solution was calculated considering activity coefficients [24, 25] and used to confirm the accuracy of the used $\mathrm{pH}$ meter, CP-411, manufactured 
by Dr. Kornder (Germany). This $\mathrm{pH}$ value was used to convert the determined potential values to the RHE scale according to Equation 1:

$$
E_{\mathrm{RHE}}=E_{\mathrm{Hg} / \mathrm{HgO}}+0.059 \mathrm{pH}+E_{\mathrm{Hg} / \mathrm{HgO}}^{0}
$$

Electrochemical impedance spectroscopy (EIS) was measured at open circuit potential (OCP) in the frequency range from $50 \mathrm{kHz}$ to $50 \mathrm{~Hz}$ with an AC perturbation of $10 \mathrm{mV}_{\mathrm{pp}}$ to determine the uncompensated solution resistance. A conditioning of the electrodes was applied by recording two cyclic voltammograms (CV) from $0.276 \mathrm{~V}$ to $0.876 \mathrm{~V}$ vs. $\mathrm{Hg} / \mathrm{HgO} / 0.1 \mathrm{M} \mathrm{KOH}$ reference electrode (1.2 V$1.8 \mathrm{~V}$ vs. RHE) at $10 \mathrm{mV} / \mathrm{s}$ at a rotation rate of $1600 \mathrm{rpm}$. This rotation speed was sufficient for effective removal of formed oxygen bubbles from the electrode surface. The third CV was recorded in the same potential range at $10 \mathrm{mV} / \mathrm{s}$ and the measured current was normalized with respect to the geometric electrode area. For each sample, three identical electrodes were prepared and characterized. All the reported potentials are $\mathrm{iR}$ corrected. The CVs were converted to LSVs using the "lowess" function in Origin 2015 software and averaged, and the determined deviations were used as error bars.

\subsection{Preparation and characterization of a $\mathrm{CoFe}-\mathrm{OH}$ material library}

A $1 \times 10 \mathrm{~cm}^{2}$ fragment of a thermally oxidized Si wafer $\left(1.5 \mu \mathrm{m} \mathrm{SiO} \mathrm{S}_{2}\right)$ coated with $100 \mathrm{~nm}$ Ni was used as the substrate. The Si wafers (Si(100), 4 inch in diameter), were from Wacker (Germany) and were received pre-oxidized. Pt and Ti were cosputtered onto the $\mathrm{Si} / \mathrm{SiO}_{2}$ wafer by Magnetron sputtering in the group of Prof. Alfred Ludwig, Ruhr-University Bochum. A $2 \times 10 \mathrm{~cm}^{2} \mathrm{Si} / \mathrm{SiO}_{2} /(\mathrm{Ti}) \mathrm{Pt}$ stripe was fixed at a distance of $2 \mathrm{~cm}$ from the working electrode in a plane-parallel configuration and connected as counter electrode. $\mathrm{A} \mathrm{Ag} / \mathrm{AgCl} / 3 \mathrm{M} \mathrm{KCl} / 0.1 \mathrm{M} \mathrm{KNO}_{3}$ double junction electrode was used as the reference electrode. The working electrode was vertically fixed on a motorized Z-stage and dipped into the precursor solution stepwise in $3 \mathrm{~mm}$ increments. After each movement, three electrodeposition cycles were applied using CV parameters as for Ni-RDE. The number of the deposition steps was 13, which resulted in a stepped thickness gradient along the library. The morphology of the $\mathrm{CoFe}-\mathrm{OH}$ materials library was examined by means of a Quanta 3D FEG scanning electron microscope (FEI) operated at $20.0 \mathrm{kV}$ at different locations (measurements areas - MA) on the sample. EDX was performed using an integrated Oxford INCA X-act detector. Each EDX measurement point had a size of approximately $400 \mu \mathrm{m} \times 600 \mu \mathrm{m}$. 


\subsection{Preparation of $\mathrm{CoFe}-\mathrm{OH} / \mathrm{Ni}$-foam electrodes}

Cleaning of Ni-foam substrates was performed by ultrasonication in $10 \% \mathrm{KOH}$ for $5 \mathrm{~min}$ in order to remove any residues, followed by thorough rinsing with deionized water, 5 min treatment with $30 \% \mathrm{H}_{2} \mathrm{SO}_{4}$ to remove any surface oxides and hydroxides, and finally, by thorough rinsing with deionized water and isopropanol. After drying in a nitrogen stream, the substrates were immediately used for further modifications. Microstructuring of $1 \times 1 \times 0.15 \mathrm{~cm}^{3}$ Ni-foam pieces was performed galvanostatically at $1 \mathrm{~A}$ for $60 \mathrm{~s}$ using a $10 \mathrm{~A}$ Metrohm current booster in a three-electrode set-up with another piece of Ni-foam as counter electrode and $\mathrm{Ag} / \mathrm{AgCl} / 3 \mathrm{M} \mathrm{KCl}$ as reference electrode. The high current density was needed for evolution of hydrogen bubbles, which acted as template in order to develop a morphology with enhanced surface area [26]. $0.1 \mathrm{M} \mathrm{NiSO}_{4}$ mixed with $2 \mathrm{M} \mathrm{NH}_{4} \mathrm{Cl}$ at $\mathrm{pH} 3.5$ (adjusted using $\mathrm{HCl}$ ) was used as the plating electrolyte. After structuring, the substrates were thoroughly rinsed with deionized water and isopropanol. After drying in a nitrogen stream, the substrates were immediately used for further modifications. Deposition of $\mathrm{CoFe}-\mathrm{OH}$ films on Ni-foam was performed in a standard three-electrode cell using identical parameters as for RDE modification. The used precursor electrolyte consisted of $21 \mathrm{mM} \mathrm{Fe}\left(\mathrm{NO}_{3}\right)_{3}, 50 \mathrm{mM}$ $\mathrm{Co}\left(\mathrm{NO}_{3}\right)_{2}$ in $0.5 \mathrm{M} \mathrm{KNO}_{3}$ (native $\mathrm{pH}$ 2.15). After modification with $\mathrm{CoFe}-\mathrm{OH}$, the electrodes were thoroughly rinsed with deionized water and immediately used for long-term tests in flow cells.

\subsection{Electrochemical measurements on Ni-foam electrodes}

All measurements were performed using a VMP3 multi potentiostat (BioLogic) controlled with the EC-LAB 10.44 software. Half-cell tests on the Ni-foam electrodes were conducted in specifically designed flow cells with three-electrodes configuration with independent anolyte and catholyte compartments. The anode and cathode were separated by a hydroxide exchange membrane (Membrasenz), keeping the electrodes in a zero-gap configuration. Unmodified Ni-foam with double thickness compared to the working electrode was used as counter electrode, and a double junction $\mathrm{Ag} / \mathrm{AgCl} / 3 \mathrm{M} \mathrm{KCl} / 1 \mathrm{M} \mathrm{KOH}$ electrode (212 mV vs. NHE) as reference electrode. One molar $\mathrm{KOH}$ solution with the concentration controlled by titration with KHP was used as electrolyte. The $\mathrm{pH}$ of the electrolyte was measured using a $\mathrm{pH}$ electrode (CP-411), purposely designed for measuring the $\mathrm{pH}$ of strongly alkaline electrolytes. The accuracy of the $\mathrm{pH}$ meter was confirmed periodically by calculating the electrolyte $\mathrm{pH}$ considering activity coefficients [24, 25]. Circulation of the electrolyte through the flow-through electrochemical cell was performed using a WPDC-10.5L circulation pump (Rotek). Five hundred milliliter 
of the electrolyte circulating in each compartment was stored in external PVC containers. The anolyte was initially saturated with $\mathrm{O}_{2}$, and the catholyte with Ar. The stability test was based on a galvanostatic stability (GSS) test protocol reported earlier [27]. The open circuit potential (OCP) was determined at the beginning of each cycle followed by EIS measurement performed at OCP from $50 \mathrm{kHz}$ to $5 \mathrm{kHz}$ with $10 \mathrm{mV}$ AC perturbation. The pumping system was then activated and the electrode brought into a working state by galvanodynamic sweep (GDS), which was run from zero current to $400 \mathrm{~mA}$ at a rate of $5 \mathrm{~mA} / \mathrm{s}$. The recorded currentpotential values were used for determination of Tafel slopes. The current interrupt (CI) technique ( $\mathrm{I}=400 \mathrm{~mA}, \mathrm{t}=50 \mathrm{~ms}, \mathrm{~d} t=0.2 \mathrm{~ms}$ ) was used for determination of the uncompensated resistance. GSS was run at $400 \mathrm{~mA}$ for $1 \mathrm{~h}$. EIS at $800 \mathrm{mV}$ vs. $\mathrm{Ag} / \mathrm{AgCl} / 3 \mathrm{M} \mathrm{KCl}$ was recorded in order to evaluate the charge transfer resistance. After the stability test the cell was switched to OCP, the pumping system was deactivated and the cycle was repeated. The recorded potential values were iR corrected using the uncompensated resistance values determined by means of the current interrupt measurements performed at the beginning of each test cycle and recalculated to the RHE scale.

\subsection{Raman measurements}

Raman spectra were acquired using a Jobin-Yvon iHR55 Raman spectrometer (Horiba), equipped with a $532 \mathrm{~nm}$ laser source. A 60x immersible objective lens (Olympus) was used to focus the laser beam to about average $1 \mu \mathrm{m}$ diameter spot size. The exposure time was $30 \mathrm{~s}$ and the laser power was kept at $5 \mathrm{~mW}$. For in situ Raman spectra acquisition of $\mathrm{CoFe}-\mathrm{OH}$ films modified on Ni-RDEs, a special electrochemical cell was built, which consisted of an acrylic body with an integrated $\mathrm{Ni}$-foam counter electrode, a $\mathrm{Ag} / \mathrm{AgCl} / 3 \mathrm{M} \mathrm{KCl} / 10 \mathrm{mM} \mathrm{KOH}$ double junction reference electrode and Ni-RDE fixation O-ring. Air saturated $0.1 \mathrm{M} \mathrm{KOH}$ was used as electrolyte. The Ni-RDE modified with the catalyst film was covered with the electrolyte and the protected immersible objective lens was placed above the electrode surface.

\section{Results and discussion}

\subsection{Electrochemical deposition of $\mathrm{CoFe}-\mathrm{OH}$}

Deposition of CoFe-OH films was carried out electrochemically by inducing a local positive shift in the $\mathrm{pH}$ value at the electrode surface by reduction of nitrate 
anions (Equation 2). The generated hydroxide ions induce precipitation of the respective metal hydroxides $[9,28]$.

$$
\begin{aligned}
& \mathrm{NO}_{3}{ }^{-}+\mathrm{H}_{2} \mathrm{O}+2 \mathrm{e}^{-} \rightarrow \mathrm{NO}_{2}{ }^{-}+2 \mathrm{OH}^{-} \\
& \mathrm{NO}_{3}{ }^{-}+7 \mathrm{H}_{2} \mathrm{O}+8 \mathrm{e}^{-} \rightarrow \mathrm{NH}_{4}{ }^{+}+10 \mathrm{OH}^{-} \\
& \mathrm{Me}^{\mathrm{x}+}+\mathrm{xOH}^{-} \rightarrow \mathrm{Me}(\mathrm{OH})_{\mathrm{x}}
\end{aligned}
$$

Co-precipitation of precursor solutions containing $\mathrm{Co}^{2+}$ and $\mathrm{Fe}^{3+}$ ions results in the formation of $\mathrm{Fe}$ and $\mathrm{Co}$ double hydroxides $(\mathrm{CoFe}-\mathrm{OH})$ [18]. The ratio of the metals in the obtained solid precipitate is usually identical to that in the precursor solution. Cyclic voltammetry was employed for the deposition as it allows to conveniently monitor changes in the redox behavior of the deposited metal hydroxides as well as quantitative control of the electrodeposit by the number of voltammetric cycles. The $\mathrm{CoFe}-\mathrm{OH}$ double hydroxide films were electrodeposited from a precursor electrolyte consisting of $\mathrm{Co}(\mathrm{II})$ - and $\mathrm{Fe}(\mathrm{III})$-nitrate in $\mathrm{KNO}_{3}$ as supporting electrolyte and nitrate ion source. For better control of the electrodeposition process, the electrolyte was saturated with Ar in order to exclude the possibility of any $\mathrm{pH}$ shift caused by the reduction of oxygen. The concentration of $\mathrm{Co}(\mathrm{II})$ and $\mathrm{Fe}(\mathrm{III})$ in the electrolyte, as well as the potential range and scan rate were experimentally optimized. High quality deposits were obtained from an electrolyte consisting of $0.5 \mathrm{M} \mathrm{KNO}_{3}, 50 \mathrm{mM} \mathrm{Co}\left(\mathrm{NO}_{3}\right)_{2}$ and variable concentration of $\mathrm{Fe}\left(\mathrm{NO}_{3}\right)_{3}(0-40 \mathrm{mM})$ in the potential range from $0 \mathrm{mV}$ to $-800 \mathrm{mV}$ vs. $\mathrm{Ag} / \mathrm{AgCl} / 3 \mathrm{M} \mathrm{KCl}$ at a scan rate of $100 \mathrm{mV} / \mathrm{s}$. Multiple electrodes were prepared using precursor solutions with different $\mathrm{Fe} / \mathrm{Co}$ ratios and a loading defined by applying 25 deposition cycles. The compositions of the used precursor electrolyte solutions are listed in Table 1. The maximum Fe content in the precursor electrolyte was $44 \mathrm{~mol} . \%$. A higher iron(III) content resulted in a significant drop of the $\mathrm{pH}$ value of the precursor solution and formation of unstable films with irreproducible OER activity.

Typical features of the voltammograms recorded during electrochemical deposition of the $\mathrm{CoFe}-\mathrm{OH}$ films on a Ni-RDE from an Ar saturated solution containing $61 \mathrm{mM} \mathrm{Co}\left(\mathrm{NO}_{3}\right)_{2}, 26 \mathrm{mM} \mathrm{Fe}\left(\mathrm{NO}_{3}\right)_{3}$ and $0.5 \mathrm{M} \mathrm{KNO}_{3}$ are shown in Figure 1a. During the first deposition cycle, a reduction current starting at about $-400 \mathrm{mV}$ was observed, which is attributed to the reduction of $\mathrm{NO}_{3}{ }^{-}$ions at the $\mathrm{Ni}$ surface. After the Ni-RDE surface is completely covered by the precipitated metal hydroxides film, the overpotential for $\mathrm{NO}_{3}{ }^{-}$reduction increases leading to disappearance of the $\mathrm{NO}_{3}{ }^{-}$reduction peak. Hence, during the subsequent deposition cycles, the reduction of $\mathrm{NO}_{3}{ }^{-}$commenced at more negative potentials.

The freshly prepared electrodes were rinsed with water and immediately evaluated with respect to their OER activity. A broad oxidation peak corresponding to 
Tab. 1: Compositions of the used precursor electrolyte solutions.

\begin{tabular}{lrrrr}
\hline $\mathrm{C}\left(\mathrm{Co}\left(\mathrm{NO}_{3}\right)_{2}\right), \mathrm{mM}$ & $\mathrm{C}\left(\mathrm{Fe}\left(\mathrm{NO}_{3}\right)_{3}\right), \mathrm{mM}$ & $\mathrm{C}\left(\mathrm{KNO}_{3}\right), \mathbf{M}$ & $\mathrm{Fe} \mathrm{mol} \%^{\mathrm{a}}$ & $\mathrm{pH}$ \\
\hline 64 & 0 & 0.5 & 0.0 & 4.17 \\
64 & 0.06 & 0.5 & 0.1 & 3.97 \\
64 & 0.19 & 0.5 & 0.3 & 3.57 \\
64 & 0.66 & 0.5 & 1.0 & 3.23 \\
64 & 1.97 & 0.5 & 3.0 & 2.73 \\
63 & 7.0 & 0.5 & 10 & 2.44 \\
61 & 26 & 0.5 & 30 & 2.04 \\
50 & 33 & 0.5 & 40 & 2.10 \\
50 & 41 & 0.5 & 45 & 2.07 \\
\hline
\end{tabular}

a(Fe/Co fraction).

the oxidation of $\mathrm{Co}^{2+}$ to $\mathrm{Co}^{3+}$ was observed prior to oxygen evolution (Figure 1b). The peak height dropped after the first voltammetric cycle due to the irreversible oxidation of cobalt in the bulk $[19,26] .^{1}$

The first half-cycles of the OER recorded for samples deposited from precursor solutions with different Fe concentrations are shown in Figure 2a. The $\mathrm{Fe}^{3+}$ content in the electrolyte ${ }^{2}$ influences the position of the $\mathrm{Co}^{2+} \rightarrow \mathrm{Co}^{3+}$ oxidation peak. The oxidation peak potential shifts towards lower potentials with increasing iron content up to $10 \mathrm{~mol} . \%$. This is an inverse behavior compared to that reported by Burke et al. [19], who showed that the addition of iron made the oxidation of $\mathrm{Co}(\mathrm{OH})_{2}$ to $\mathrm{CoOOH}$ more difficult. This difference is most likely due to the initial structure of the obtained $\mathrm{CoFe}-\mathrm{OH}$ owing to the fact that $\mathrm{Fe}^{3+}$ was used as the Fe precursor. The dependence of the peak potential on the iron content indicates strong electronic coupling between Fe and Co in the film. Further increase of the Fe content beyond 10 mol.\% led to a reversal of this trend with the oxidation peak potential shifting to higher potentials. In addition, the integrated charge associated with the oxidation of $\mathrm{Co}(\mathrm{OH})_{2}\left(\mathrm{Co}^{2+}\right)$ to $\mathrm{CoOOH}\left(\mathrm{Co}^{3+}\right)$ gets smaller indicating diminished availability of these redox active species. A possible reason for this effect could be that the incorporated Fe ions hinder the kinetics of $\mathrm{Co}^{2+}$ oxidation in the film. Thus, there is a kind of inverted volcano-type dependence of the peak potential position on Fe-content. The OER activity of $\mathrm{CoFe}-\mathrm{OH}$ films with variable Fe contents are presented in Figure $2 \mathrm{~b}$. The linear sweep voltammograms (LSV) were obtained from averaged CVs as described in the experimental part. The Tafel

1 This oxidation is only partially irreversible. According to Burke the peak does reappear upon cathodic cycling to $-0.9 \mathrm{~V}$ vs. $\mathrm{Hg} / \mathrm{HgO}$ [17].

2 The iron content (mol.\%) in the solid was considered to be identical to that in the precursor solution. 

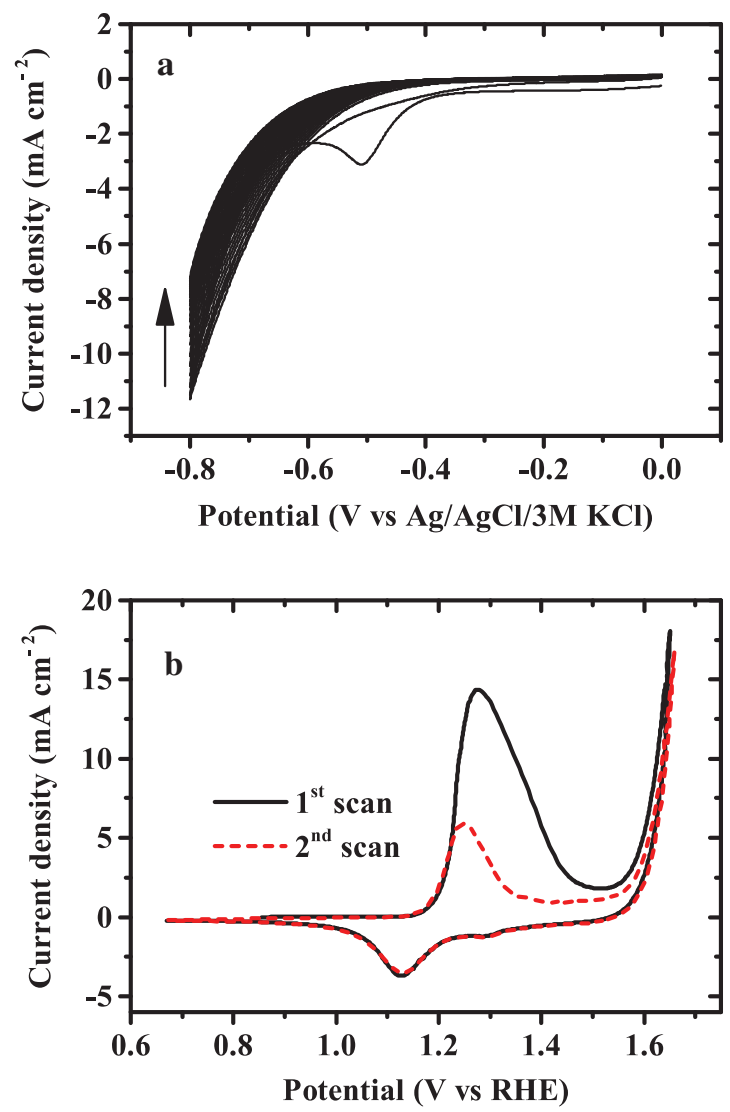

Fig. 1: (a) CV recorded during cathodic deposition of CoFe double hydroxide on a Ni RDE from an Ar saturated precursor electrolyte containing $50 \mathrm{mM} \mathrm{Co}\left(\mathrm{NO}_{3}\right)_{2}, 21 \mathrm{mM} \mathrm{Fe}\left(\mathrm{NO}_{3}\right)_{3}$ and $0.5 \mathrm{M}$ $\mathrm{KNO}_{3} . \mathrm{dE} / \mathrm{dt}=100 \mathrm{mVs}^{-1}$; (b) cyclic voltammetry of electrochemically deposited cobalt hydroxide in $0.1 \mathrm{M} \mathrm{KOH}$. $\mathrm{dE} / \mathrm{dt}=10 \mathrm{mVs}^{-1}$.

plots obtained from polarization curves in $0.1 \mathrm{M} \mathrm{KOH}$ for the nine $\mathrm{CoFe}-\mathrm{OH}$ electrodes are shown in Figure 2c, and the corresponding values of the Tafel slopes as function of the Fe content are shown in Figure 2d (blue marks). As indicated in the experimental part, both half-waves of the CVs were averaged and filtered, which allowed minimization of the contribution of capacitive currents. The Tafel slope dropped monotonically from $66.2 \mathrm{mV}$ for pure $\mathrm{Co}(\mathrm{OH})_{2},{ }^{3}$ indicating that the rate determining step involves a chemical step subsequent to the first electron

3 The data markers for the pure $\mathrm{Co}(\mathrm{OH})_{2}(0 \mathrm{~mol} . \% \mathrm{Fe})$ in the Figure $2 \mathrm{~d}$ were not displayed because of the logarithmic scale, but were included in the linear fitting. 

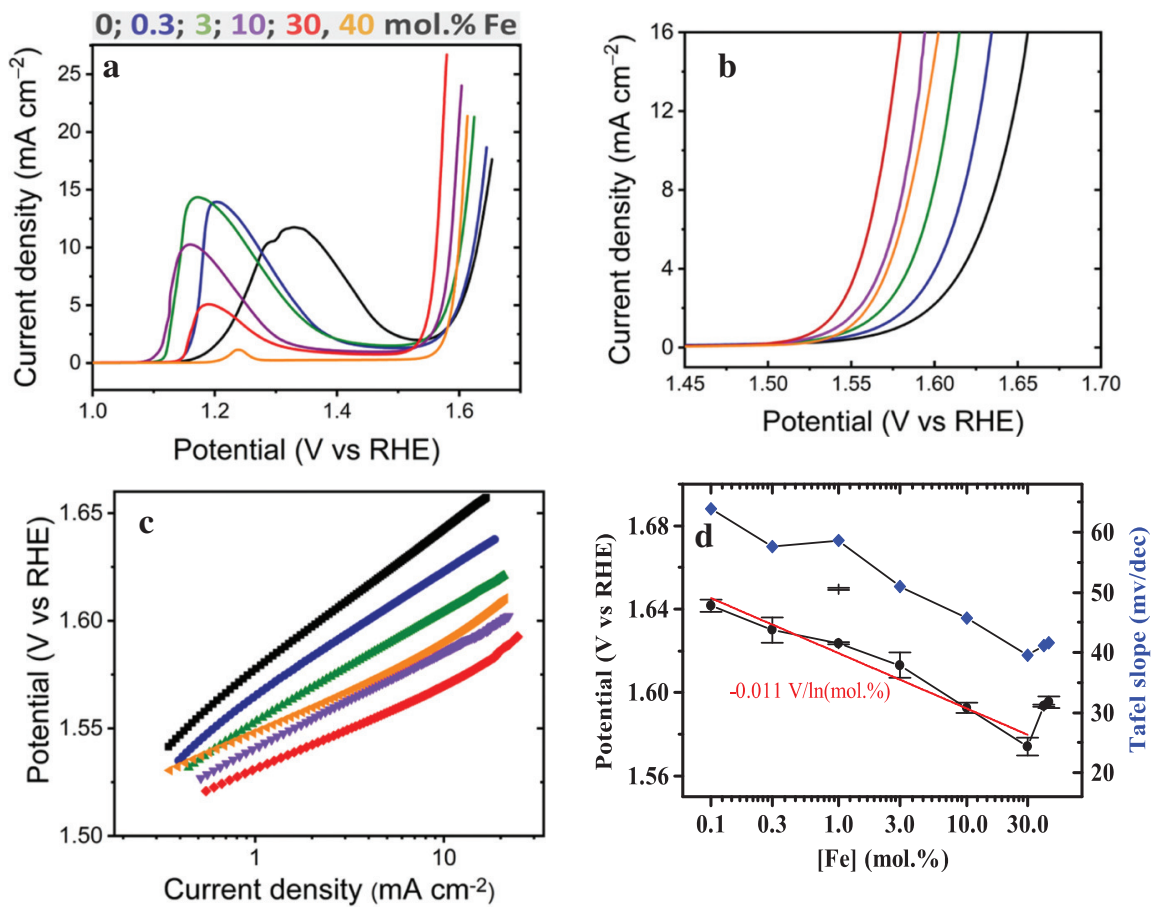

Fig. 2: (a) First half scan recorded on electrochemically deposited $\mathrm{CoFe}-\mathrm{OH}$ films with different Fe contents; $\mathrm{dE} / \mathrm{dt}=10 \mathrm{mV} \mathrm{s}^{-1}$; (b) voltammograms extracted from $\mathrm{CVs}$ of $\mathrm{Co}-\mathrm{Fe}-\mathrm{OH}$ films with different Fe contents; $\mathrm{dE} / \mathrm{dt}=10 \mathrm{mV} \mathrm{s}^{-1}$; (c) Tafel plots plotted from b; (d) Tafel slope, and the potential at $10 \mathrm{~mA} \mathrm{~cm}-2$ as a function of the Fe content in the precursor electrolyte. The electrolyte was $0.1 \mathrm{M} \mathrm{KOH}$ for all the measurements.

transfer step, to a minimum of $39.6 \mathrm{mV}$ for $\mathrm{Co}_{0.7} \mathrm{Fe}_{0.3}(\mathrm{OH})_{\mathrm{x}}$, where the second electron transfer is rate determining [29-31]. Such a low value of the Tafel slope is typical of electrocatalysis of the OER by $\mathrm{Ni}(\mathrm{Fe}) \mathrm{OOH}$ compounds, which indicates that a related or similar OER mechanism is very likely in the shown $\mathrm{CoFe}-\mathrm{OH}$ systems. The intermediate values of the Tafel slope, e.g. $51.7 \mathrm{mV}$ for $\mathrm{Co}_{0.97} \mathrm{Fe}_{0.03}(\mathrm{OH})_{\mathrm{x}}$, could not be interpreted on the premise of classic Butler-Volmer kinetics [30, 31].

The overpotentials corresponding to a current density of $10 \mathrm{~mA} \mathrm{~cm}{ }^{-2}$ as function of Fe content are depicted in Figure 2d, revealing a dependence of the OER activity on Fe-content. The overpotential at $10 \mathrm{~mA} \mathrm{~cm}^{-2}$ decreased linearly with the logarithm of the iron content up to $30 \mathrm{~mol} . \%$. On the basis of the assumption that Fe atoms serve as active or intermediate stabilizing sites [21], the reaction rate, which is directly measured as current, should be proportional to the surface concentration of these sites $-C_{\mathrm{Fe}}$ (Equation 3), where $i$ is the measured current; $A$ is a coefficient that depends on the rate constant, surface area and electrolyte 
composition; $\alpha$ is the charge transfer coefficient and $\eta$ is the overpotential):

$$
i=A C_{\mathrm{Fe}} e^{\frac{\alpha F}{k T} \eta}
$$

Rearranging Equation 3 to express the overpotential as a function of $C_{\mathrm{Fe}}$ shows that the overpotential at a given current density under fixed experimental conditions varies linearly with the natural logarithm of iron concentration (Equation 4), as observed experimentally and depicted in Figure 2d.

$$
\eta=R T \frac{\ln (i)-\ln (A)}{\alpha F}-\frac{R T}{\alpha F} \ln \left(C_{\mathrm{Fe}}\right)
$$

This dependence reveals a clear synergetic effect. Cobalt sites are active on their own, but Fe modifies cobalt active sites through electronic coupling [32]. Fe sites could also participate in the OER, however, iron hydroxide on its own is known to be a low-active OER catalyst, so interaction between Co and Fe is crucial for explaining the high OER activity. Another preposition that has been raised, which is however difficult to justify, is that the Fe centers are either the active sites while Co facilitates charge transport, or they participate in the OER along with Co as intermediate stabilizing sites [21,33]. From the value of the average slope which is $-11 \mathrm{mV} / \mathrm{ln}$ (mol.\%), obtained by linear fitting of the curve in Figure 2d, taking $\mathrm{T}=298 \mathrm{~K}$, the charge transfer coefficient $\alpha$ was calculated to be 2.33. For a one-electron transfer process $\alpha$ lies between 0 and 1. For multi-electron transfer reactions, the formally determined $\alpha$ can range from 0 up to the number of transferred electrons. If the first electron transfer is rate limiting, then $\alpha$ of the complete reaction is the $\alpha$ of the first electron transfer step and lies in the range from 0 to 1 . In the case where the $2^{\text {nd }}$ or the $3^{\text {rd }}$ electron transfer step is rate limiting, all preceding steps will each contribute 1 to the ultimate value of $\alpha$. For several metals, $\alpha$ values of 1.5 have been determined for the hydrogen evolution reaction, which can be interpreted as 1 plus $\alpha$ of the second step, if the overall reaction rate is limited by the second step. Since in the present case the value of $\alpha$ lies between 2 and 3 , the reaction is most certainly limited by a chemical step, most likely deoxygenation of a peroxide $\left(\mathrm{MO}_{2}\right)$. A more accurate description of this phenomenon is however difficult, since the exact reaction mechanism and rate determining step are not explicitly known [30, 31, 34].

Although the OER activity increased with Fe content, there is a threshold which when exceeded leads to a decline in activity, most likely due to a decline of the film conductivity [10], or segregation of Fe hydroxide. The observed threshold was 30 mol.\% Fe as shown in Figure 2b,d. A similar tendency was observed for cobalt-iron double hydroxides electrodeposited from $\mathrm{Fe}^{2+}$ precursor solutions, however, in this case, the peak OER activity was attained at 40-60 at.\% Fe [10]. 
In this study, the lowest OER overpotential was observed for an electrode deposited from a precursor electrolyte with a $\mathrm{Fe}^{3+} / \mathrm{Co}^{2+}$ ratio of 1:2.33. According to EDX data, the Fe-content in the deposited film was $31.0 \pm 2.9$ at.\%, which indicates quantitative metal hydroxide precipitation from the precursor solution.

\subsection{In-situ Raman spectra of the $\mathrm{Co}_{0.7} \mathrm{Fe}_{0.3}(\mathrm{OH})_{x}$ film}

In-situ Raman spectra were recorded for the most active $\mathrm{CoFe}-\mathrm{OH}$ electrode, $\mathrm{Co}_{0.7} \mathrm{Fe}_{0.3}(\mathrm{OH})_{\mathrm{x}}$. A freshly prepared Ni-RDE modified with $\mathrm{Co}_{0.7} \mathrm{Fe}_{0.3}(\mathrm{OH})_{\mathrm{x}}$ was fixed in a specifically designed three-electrode electrochemical cell for in situ Raman measurements and filled with $0.1 \mathrm{M} \mathrm{KOH} .{ }^{4}$ Cyclic voltammetry was performed at a scan rate of $1 \mathrm{mV} / \mathrm{s}$ with simultaneous Raman spectra acquisition in $50 \mathrm{mV}$ steps. Two scans in the potential range from 0 to $750 \mathrm{mV}$ vs. $\mathrm{Ag} / \mathrm{AgCl}$ were recorded. Because of the slow scan speed, the Co oxidation peak could not be clearly seen in the corresponding voltammogram. Therefore, the first $\mathrm{CV}$ recorded in the Raman electrochemical cell (black dotted line) Figure 3a is superimposed with a voltammogram recorded at $10 \mathrm{mV} / \mathrm{s}$ during the OER test in a regular electrochemical cell where the Co oxidation peak is well pronounced. The curves have different slopes since the voltammograms are not iR corrected and the used electrochemical cells had different resistances. The Raman spectra were accumulated for $50 \mathrm{~s}$ at each potential. The baseline was manually subtracted from each acquired Raman spectrum and non-linear curve fitting was applied for deconvolution of the spectra. Furthermore, the overall signal intensity was decaying during the course of the measurements because of surface blockage by oxygen bubbles.

The acquired Raman spectra as function of the applied potential (vs. $\mathrm{Ag} / \mathrm{AgCl} / 3 \mathrm{M} \mathrm{KCl}$ ) are shown in Figure 3b. In the Raman spectrum recorded at $0 \mathrm{mV}$, one dominant peak at $589 \mathrm{~cm}^{-1}$, and two weaker peaks at $427 \mathrm{~cm}^{-1}$ and at $496 \mathrm{~cm}^{-1}$ could be resolved in the wavenumber range between 200 and

4 There was an attempt to identify the crystalline phase of the $\mathrm{Co}_{0.7} \mathrm{Fe}_{0.3}(\mathrm{OH})_{\mathrm{x}}$ compound deposited on the Ni-foam by X-ray diffraction (XRD). The tree most intense reflections found at $44.5^{\circ}, 51.9^{\circ}$ and $76.4^{\circ}$ correspond to $\mathrm{Ni}$ (111), $\mathrm{Ni}$ (200) and $\mathrm{Ni}$ (220), respectively. Hydroxide films prepared by precipitation are rather deposited not in the thermodynamically most stable, but in kinetically most accessible form. Therefore, these films are typically amorphous or only poorly crystalline. Because of low amount of catalyst and probably its poor crystallinity, the above-mentioned reflections had intensities three orders of magnitude less, than those of the $\mathrm{Ni}$-substrate. Nevertheless, three typical for Co-Fe LDH structures reflections could be resolved at $22^{\circ}(006), 34^{\circ}(012)$ and $59^{\circ}(110)$ (JCPDS card No. 50-0235). The (003) basal peak at $12^{\circ}$ could not be seen because of the rising line, however, this does necessarily exclude the possibility that the prepared hydroxide had a layered structure. 

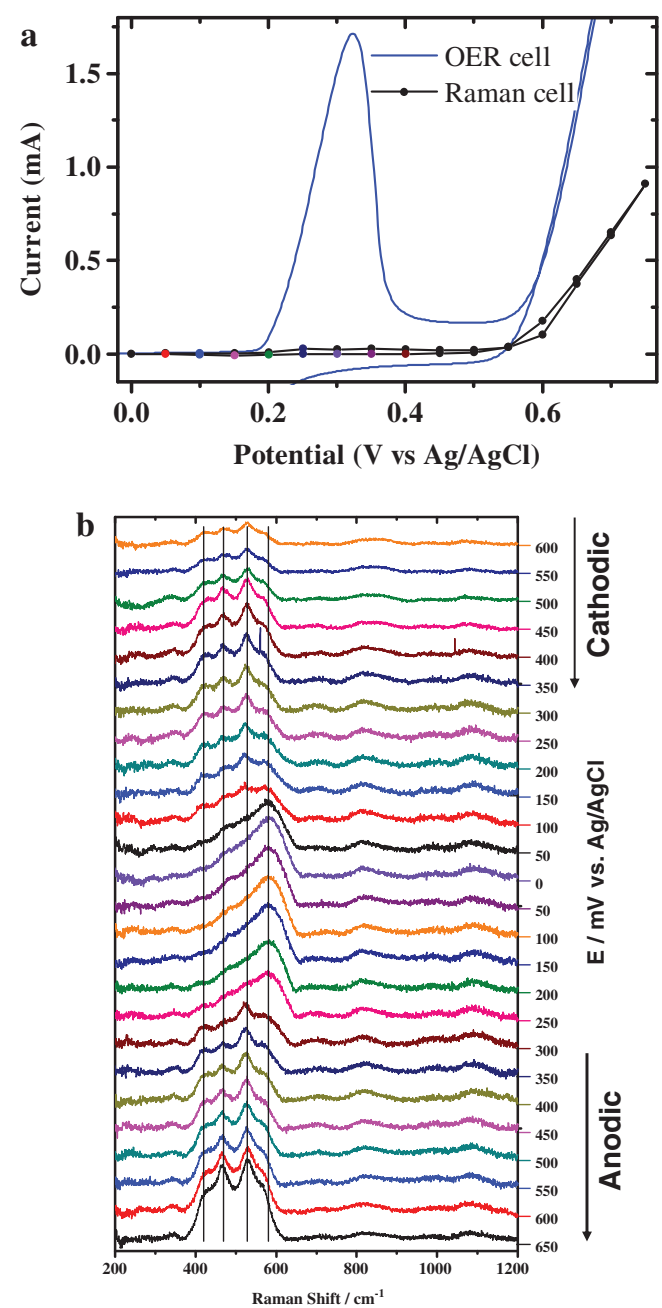

Fig. 3: (a) Cyclic voltammograms of a Ni-RDE electrode modified with $\mathrm{Co}_{0.7} \mathrm{Fe}_{0.3}(\mathrm{OH})_{x}$ recorded in a conventional electrochemical cell at $10 \mathrm{mV} / \mathrm{s}$ (a), and in a custom made electrochemical cell for in situ electrochemistry - Raman spectroscopy at a scan rate of $1 \mathrm{mV} \mathrm{s}^{-1}$ in $\mathrm{KOH}$ solution at pH 10; (b) Raman spectra recorded during the anodic and cathodic potential scans on a $\mathrm{CO}_{0.7} \mathrm{Fe}_{0.3}(\mathrm{OH})_{x}$ modified $\mathrm{Ni}-\mathrm{RDE}$ in $\mathrm{KOH}$ solution of $\mathrm{pH} 10$. A $532 \mathrm{~nm}$ laser source was used at a power of $5 \mathrm{~mW}$ and $30 \mathrm{~s}$ data acquisition time.

$800 \mathrm{~cm}^{-1}$. The relative intensity of these peaks did not substantially change as the potential was increased from 0 to $200 \mathrm{mV}$. Neither oxygen evolution, nor $\mathrm{Co}^{2+} \rightarrow \mathrm{Co}^{3+}$ oxidation are expected to take place in this potential range. Above $200 \mathrm{mV}$, the oxidation of $\mathrm{Co}^{2+}$ to $\mathrm{Co}^{3+}$ or to even a higher oxidation state of 
cobalt is expected to occur. We visually observed that the catalyst film, which was initially brown-greenish, turned permanently black, even upon reversal of the applied potential. Due to enhanced absorption of the laser irradiation, the spectrum acquired at $200 \mathrm{mV}$ had a non-linear baseline, which was difficult to correct. Nevertheless, distinct changes of the features of the Raman spectra could be observed. The peaks at 496 and $589 \mathrm{~cm}^{-1}$ disappeared and new peaks emerged at 465,531 and $575 \mathrm{~cm}^{-1}$. The pair of the peaks at 465 and $531 \mathrm{~cm}^{-1}$ is assigned to the vibration of $\mathrm{Co}-\mathrm{O}$ in $\mathrm{CoOOH}$, while the peak at $575 \mathrm{~cm}^{-1}$ is ascribed to the presence of a layered hydroxide structure [35]. The peak at $465 \mathrm{~cm}^{-1}$ is most likely due to $\mathrm{E}_{\mathrm{g}}$ symmetric bending of $\mathrm{OCoO}$ in $\mathrm{CoOOH}[35,36]$, although it is evidently shifted to a slightly lower wavenumber due to interaction with Fe and the support. The appearance of these Raman peaks coincide with the appearance of the $\mathrm{Co}^{2+}$ to $\mathrm{Co}^{3+}$ oxidation peak in the voltammogram and reflects structural changes in the catalyst. No discernible changes in the features of the spectrum could be observed upon further increase of the potential up to $550 \mathrm{mV}$ and further above $550 \mathrm{mV}$, where oxygen evolution is expected to occur, indicating no further structural changes of the catalyst at OER conditions. When the potential was reversed, features of the spectrum identical to those observed during the anodic scan resurfaced during the cathodic sweep. This indicates reversibility of the structural changes, associated with the interconversion between the $\mathrm{Co}^{2+}$ and $\mathrm{Co}^{3+}$ states.

However, the intensity of the Raman signals decayed gradually during the measurements, for example, the intensity of peak at $589 \mathrm{~cm}^{-1}$ was 25 times lower at the end of the second CV scan as compared to its intensity at the beginning of the experiment. The intensity of the four peaks at $427 \mathrm{~cm}^{-1}, 465 \mathrm{~cm}^{-1}, 531 \mathrm{~cm}^{-1}$, and at $575 \mathrm{~cm}^{-1}$ gradually decreased in the potential range from 700 to $350 \mathrm{mV}$. Below this potential, these peaks disappeared and the peaks at $496 \mathrm{~cm}^{-1}$ and at $589 \mathrm{~cm}^{-1}$ reappeared during $\mathrm{Co}^{3+} \rightarrow \mathrm{Co}^{2+}$ reduction further corroborating potential induced reversibility of the $\mathrm{Co}^{2+} / \mathrm{Co}^{3+}$ species. The most prominent peaks ascribed to $\mathrm{CoOOH}$ formation in a cobalt hydroxide modified with various amounts of Fe were observed at $503 \mathrm{~cm}^{-1}$ and $568 \mathrm{~cm}^{-1}$ [37]. The characteristic peaks of cobalt oxides electrodeposited on gold for $\mathrm{CoOOH}$ formation were observed at $503 \mathrm{~cm}^{-1}$ and at $565 \mathrm{~cm}^{-1}$ [38]. The observations thus clearly indicate the transition of the cobalt sites from $\mathrm{Co}^{2+}$ to $\mathrm{Co}^{3+}$, formation of a cobalt oxyhydroxide $(\mathrm{CoOOH})$ intermediate prior to oxygen evolution. Considering the fact that the presence of Fe contributed to enhancement of the OER, its contribution to constitution or modification of the active sites needs to be investigated in detail. A decline in OER activity was observed when Fe was replaced with $\mathrm{Al}$ in a CoFe-double layered hydroxide structure [23], which underscored the essential role of Fe in enhancing the OER although its involvement as the active 
site, part of the active site $[19,39]$, or active site modifier [40, 41], remain to be clarified.

\subsection{Tailoring the catalyst film thickness}

The activity of a functional electrode does not only depend on the intrinsic activity of the catalyst, but also on the thickness and stability of the catalyst film. It was shown for thin films of cobalt phosphate based OER catalysts that an optimum film thickness exists beyond which the OER activity remains constant or even declines [28].

For photoelectrocatalysts, the optimal film thickness is a balance between sufficient light absorption, which increases with film thickness, and the resistance of the film, which decreases with thickness [42]. In order to determine the optimal thickness for the $\mathrm{CoFe}-\mathrm{OH}$ catalysts, six electrodes with different loadings were prepared by varying the number of deposition cycles and determining their influence on the OER activity (Figure 4a). There was substantial increase of the OER activity going from 1, 3 and 10 deposition cycles. Further increase of the number of deposition cycles did not lead to any further activity enhancement. An important observation was gradation in the optical appearance of the resulting films depending on the number of deposition cycles. Whereas films deposited by less than 35 continuous CV deposition cycles were compact and mechanically stable, thicker films had a distinct two-layer structure with the upper layer being mechanically unstable, to the extent of peeling off during rinsing of the prepared electrodes. The residual film could not be optically differentiated from the films prepared by 25 continuous CV deposition cycles, and they exhibited identical OER performance. In order to investigate this phenomenon, $\mathrm{C} \mathrm{Co}_{0.7} \mathrm{Fe}_{0.3}(\mathrm{OH})_{\mathrm{x}}$ materials library (ML) with varying film thickness was prepared using a gradient deposition tool as described in the experimental part. The ML had a stepped thickness gradient with 13 steps [measuring areas (MA)], with thicknesses corresponding to: 0 for the unmodified substrate (MA 1), to 36 deposition cycles (MA 13). The film composition was determined by EDX at several locations within each MA. The average Fe-content in the various films are presented in Figure 5a. The morphology of each MA was evaluated using SEM and the obtained micrographs are depicted in Figure 5b.

The activity determined by RDE measurements was correlated with the composition and morphology of the films. There were three distinct thickness domains with different morphologies, composition and optical appearance. Applying three deposition cycles resulted in the formation of thin flat hydroxide films with visibly apparent low active surface area (MA 2). Nevertheless, the substrate seems to be 

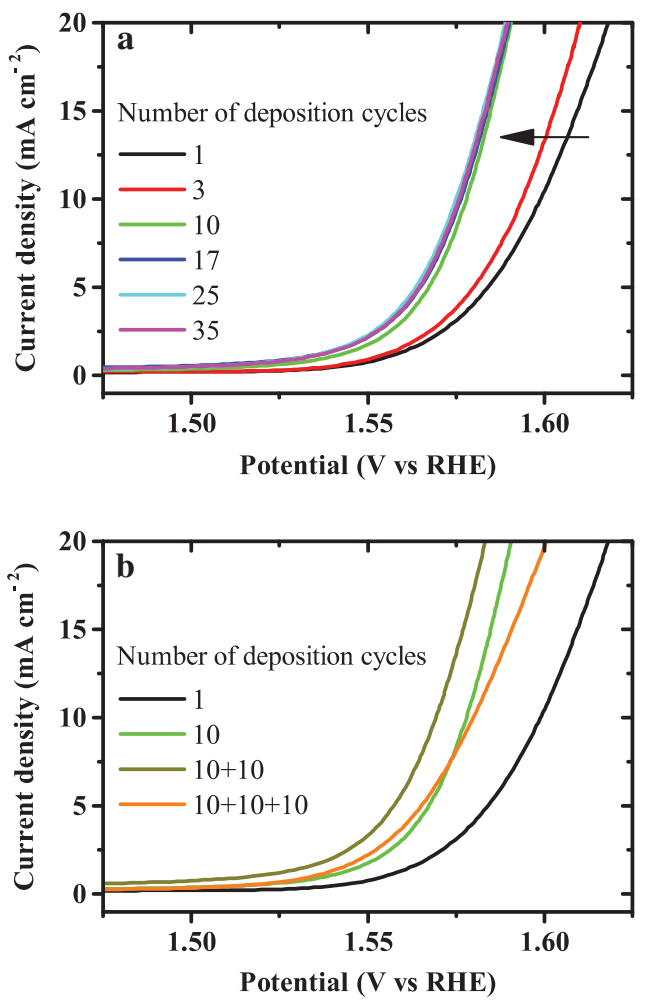

Fig. 4: $\mathrm{OER}$ activity of $\mathrm{CoFe}-\mathrm{OH}$ catalyst films in $0.1 \mathrm{M} \mathrm{KOH}$ as a function of the number of deposition cycles, (a) for the case of continuous CV deposition, and (b) with stop intervals to replenish the interfacial concentration of the electrolyte. The scan rate during the CVs was $10 \mathrm{mV} \mathrm{s}^{-1}$.

fully covered by the hydroxides in this MA. In the MAs with film thickness corresponding to 3-12 deposition cycles, flake-like structures typical of d-metal hydroxides were obtained (Figure $5 b-6-12,12 a)$. Considering the three-dimensionality of the film, much higher active surface areas would be expected, which is supported by rapid OER activity increase as shown in Figure 4a. The corresponding region of the ML had a green-yellowish color, which most probably corresponds to a mixture of the colors of the individual metal hydroxides, Co and Fe hydroxides. All films from 15 to 30 deposition cycles had a rather yellowish tint, which is attributed to increase of the Fe content. The films also had a much denser structure (see Figure 5b-15-30, 30a), compared to the thinner films.

The OER activity of the films within this thickness domain was independent of the film thickness. Further increase of the film thicknesses resulted in a third 

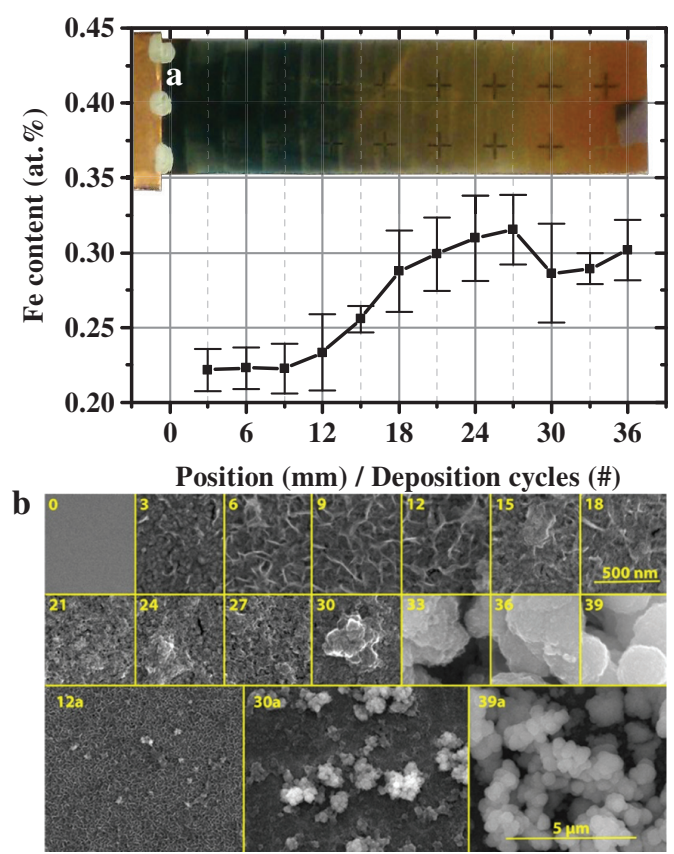

Fig. 5: (a) Photographic image of a $\mathrm{Co}_{0.7} \mathrm{Fe}_{0.3}(\mathrm{OH})_{x}$ materials library and corresponding compositional data obtained by SEM with integrated EDX analysis; (b) morphology of the $\mathrm{Co}_{0.7} \mathrm{Fe}_{0.3}(\mathrm{OH})_{\mathrm{x}}$ films obtained by applying different numbers of deposition cycles (indicated as numbers).

thickness domain, with two distinguishable layer morphologies. Whereas the first layer had a flake-like structure exactly identical to the MAs in the first thickness domain, the top layer consisted of large spherical particles, which coalesced with each other (Figure 5b - 33-39, 39a). This top film had a strong brown color similar to pure $\mathrm{Fe}(\mathrm{OH})_{3}$ and was mechanically unstable.

EDX examination of the film composition revealed a clear dependence of the film composition on the number of deposition cycles, both of which correlated with the OER activity of the films. The above-mentioned three thickness domains could be clearly seen by EDX as well. The films formed by 3, 6 and 9 deposition cycles were not quantitatively precipitated and had an average iron content of $22.2 \pm 1.6$ at.\%. From 12 to 18 deposition cycles, the Fe-content gradually increased from $23.3 \pm 2.5$ at.\% to $28.8 \pm 2.7$ at.\%, reaching a nearly constant Fe-content of $30.8 \pm 2.8$ at.\% for the films obtained by applying 21-27 deposition cycles. The OER activity in this domain was invariant, which means, the activity in this thickness range is only governed by the composition of the films and not by the film thickness. The third domain corresponds to two-layer films, where the 
unstable Fe-rich film was delaminated, thus exposing the mixed hydroxide film with invariable OER activity. The EDX data displayed in Figure 5a was taken from a delaminated film. Such evolution of film composition with the number of deposition cycles could be explained by increase of the $\mathrm{pH}$-gradient in the proximity of the electrodes during the course of the deposition process. Since $\mathrm{Fe}^{3+}$ ions have a much narrower $\mathrm{pH}$ stability window than $\mathrm{Co}^{2+}$, the rate of $\mathrm{Fe}(\mathrm{OH})_{3}$ precipitation with increase of $\mathrm{pH}$ is expected to be faster than that of $\mathrm{Co}(\mathrm{OH})_{2}$. Correspondingly, it is impossible to continuously control the thickness and composition of the double hydroxide films by just varying the number of deposition cycles. Rotating of the electrode does not allow formation of a sufficient $\mathrm{pH}$ gradient at the electrode surface and no deposition takes place. Therefore, the deposition procedure was further modified to layer by layer deposition, in order to increase the film thickness while maintaining the film composition. Since the maximum OER activity was identical for the films deposited by 25 cycles (30.8 at.\%) and 10 cycles (with an Fe-content of $\approx 23$ at.\%), each deposition layer was chosen to be 10 cycles. The modified deposition procedure thus consisted of the following steps: after 10 cycles of electrodeposition, the Ni-electrode was rinsed with pure water, put back into the electrochemical cell and rotated for $30 \mathrm{~s}$ in order to replace the remaining rinsing water by the precursor electrolyte and further 10 deposition cycles were applied. Such successive growth of the films allowed to overcome the issue of composition change and the optimal film thickness was found to be $10+10$ as can be seen in Figure 4b. The $10+10+10$ cycles film demonstrated diminished OER activity and was obviously too thick, which was reflected in a less steep slope of the corresponding OER current attributed to increased film resistance.

\subsection{Long-term stability tests of Ni-foam based electrodes}

Four Ni-foam electrodes, of size $1 \times 1 \mathrm{~cm}^{2}$ and a thickness of $0.15 \mathrm{~cm}$, namely: non-modified Ni-foam Figure $6 \mathrm{a}, \mathrm{CoFe}-\mathrm{OH}$ decorated Ni-foam Figure $6 \mathrm{~b}$ and $\mathrm{CoFe}-\mathrm{OH}$ decorated structured Ni-foam Figure $6 \mathrm{c}$, were investigated for their OER activity and long-term stability in $1 \mathrm{M} \mathrm{KOH}$, in a custom built electrochemical flow cell, described in the experimental part.

Modification of nickel foam with the catalysts was performed following the optimized layer by layer deposition procedure. Detailed structuring and modification procedures, as well as the test protocol are described in the experimental part. The Fe-content in the catalyst films on the modified Ni-foam electrodes was determined by EDX and amounted to $21.7 \pm 1.1$ at.\%, which is in a good agreement with the results obtained for the flat electrodes with the corresponding number of deposition cycles. 

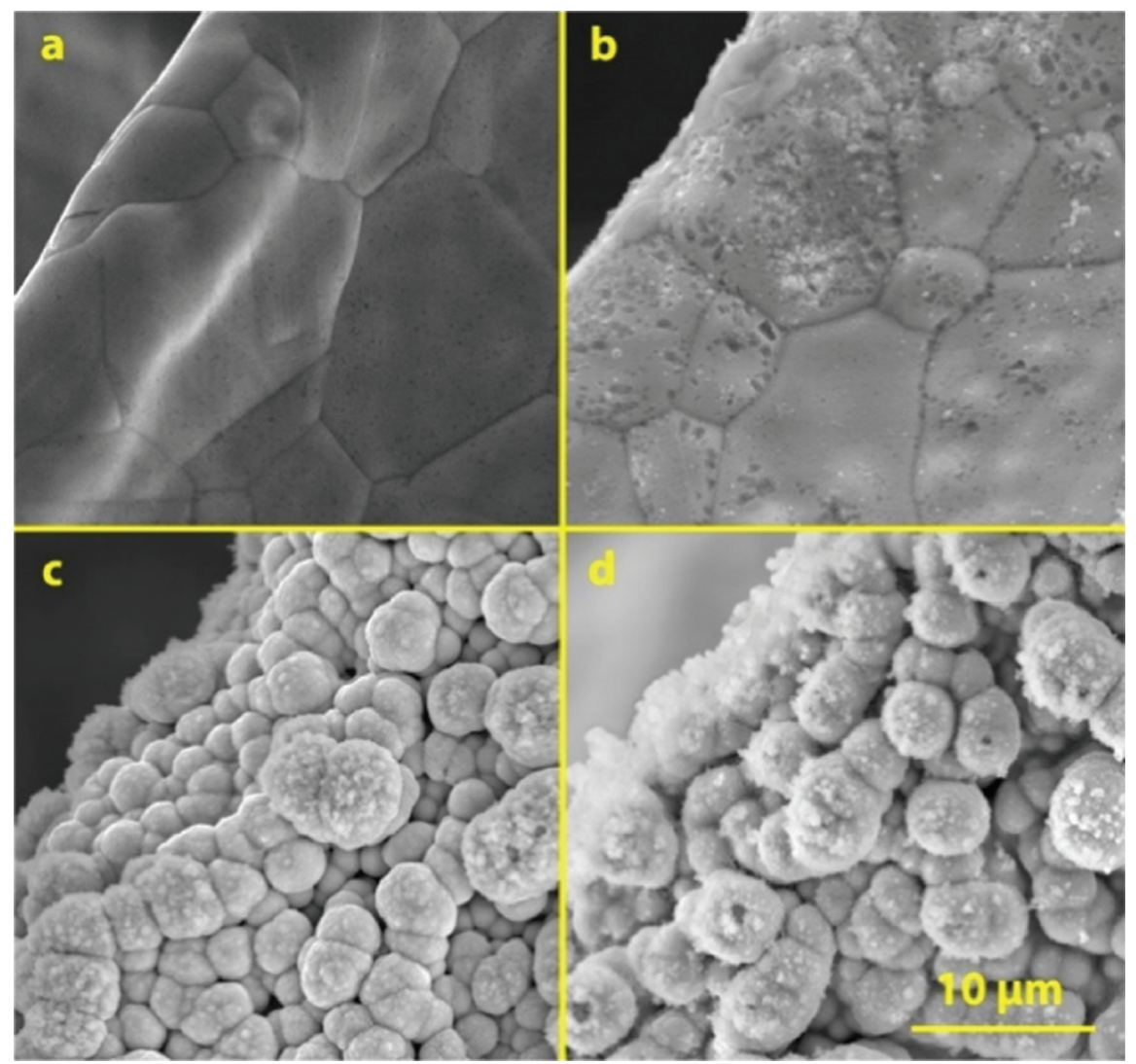

Fig. 6: SEM micrographs of (a) non-modified Ni-foam, (b) CoFe-OH modified Ni-foam, (c) microstructured Ni-foam modified with $\mathrm{CoFe}-\mathrm{OH}$, (d) sample from (c) after $320 \mathrm{~h}$ of the galvanostatic stability (GSS) test.

Figure 7a shows the galvano-dynamic sweep (GDS) curves of the four samples recorded from 0 to $400 \mathrm{~mA}$ at $5 \mathrm{~mA} \mathrm{~s}^{-1}$ with the $\mathrm{X}$ and $\mathrm{Y}$ axes exchanged in order to represent LSV-like data, although in the strictest sense, these measurements cannot be directly compared to classic LSV recorded under potential control, due to the fact that, the current sweep rate was fixed, implying that the effective potential sweep rate was not constant. Still several parameters of the electrodes could be compared semi-quantitatively using this representation of the data. For example, as can be seen, the structured Ni-foam electrode exhibited much higher capacitive currents than the non-treated Ni-foam, thus demonstrating effective enhancement of the Ni-foam surface area through microstructuring. 

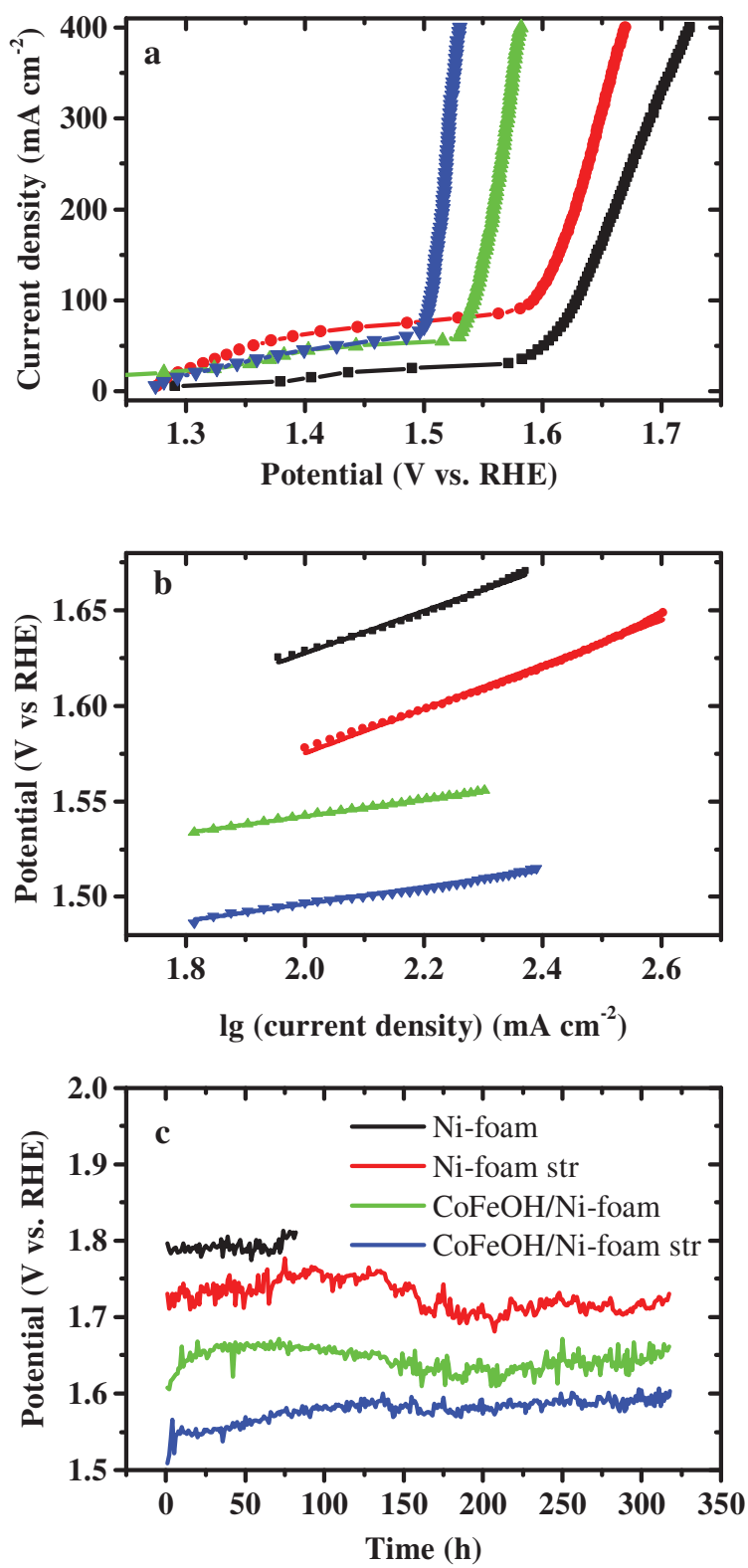

Fig. 7: (a) iR corrected GDS curves of the Ni-foam based electrodes recorded during the $3^{\text {rd }}$ GSS cycle; (b) Tafel slopes extracted from the GDS curves from (a); (c) iR corrected overpotentials at $i=400 \mathrm{~mA} \mathrm{~cm}^{-2}$ as a function of time. The curve comprised of potential values recorded at the end of each GSS cycle. 
Although onset potential is an ill-defined value in electrocatalysis, it could be roughly estimated as the $\mathrm{x}$-coordinate of the crossing point of the two linear parts in the plot. The OER onset potential determined in this way was the same, $1.6 \mathrm{~V}$, for both non-modified Ni-foam electrodes. Essentially, since structuring does not influence the intrinsic properties of the electrocatalyst, it is reasonable that the onset potential should not change. On the other hand, the onset potential for the two other electrodes was different, in this case, 1.5 and $1.54 \mathrm{~V}$ for $\mathrm{CoFe}-\mathrm{OH}$ on the structured electrode ( $\mathrm{CoFeOH} / \mathrm{Ni}$-foam str) and $\mathrm{CoFe}-\mathrm{OH} / \mathrm{Ni}$-foam electrode, respectively. It is difficult to explicitly account for this phenomenon, since the difference is obviously larger than the possible methodological error in the onset potential determination.

The GDS curves were further used for determination of Tafel slope values by plotting the recorded potential values vs. logarithm of the applied currents as shown in Figure 7b. The original and structured Ni-foam had almost identical Tafel slopes, 110.4 and $116.1 \mathrm{mV} / \mathrm{dec}$, respectively. Thus, the structuring did not influence the reaction mechanism. Assuming a single-site mechanism, a Tafel slope value close to $118.9 \mathrm{mV} / \mathrm{dec}$ indicates a high coverage of adsorbed species, implying that either $\mathrm{OH}^{-}$ion adsorption or oxygen discharge is rate-limiting $[29,30]$. The observed discrepancy of the Tafel plot for the structured Ni-foam thus corresponds to a change of the pre-exponential factor explained by surface area increase. Modification with the catalyst resulted in Tafel slopes of 43.7 and $44.0 \mathrm{mV} / \mathrm{dec}$ for the $\mathrm{CoFeOH} / \mathrm{Ni}$-foam and $\mathrm{CoFeOH} / \mathrm{Ni}$-foam str electrodes, respectively. This significant change in the Tafel slope after modification of the structured nickel foam with the catalyst is ascribed to a change in the rate-limiting step. Particularly, the observed decrease of the Tafel slope of the OER on the structured nickel foam electrodes indicates a low coverage of the surface with adsorbed species, implying that a charge transfer step involving either the water discharge reaction (hydroxylation) or formation of adsorbed oxygen is rate limiting [31].

Figure $7 \mathrm{c}$ shows iR corrected electrode potential recorded at a current density of $400 \mathrm{~mA} \mathrm{~cm}{ }^{2}$, normalized by the geometric area of the electrode $\left(1 \mathrm{~cm}^{2}\right)$, as a function of time. The curves were obtained by recording the potential at the end of each galvanostatic stability (GSS) cycle. The average potential was $1.79 \mathrm{~V}$ for the unmodified Ni-foam electrode, which remained stable for at least $80 \mathrm{h.} .^{5}$ The potential of the structured Ni-foam electrode was initially $1.73 \mathrm{~V}$ then increased during the first $140 \mathrm{~h}$ at an average rate of $0.25 \mathrm{mV} \mathrm{h}^{-1}$. During the following $30 \mathrm{~h}$, a sort of activation took place, after which the potential remained around $1.71 \mathrm{~V}$ until the end of the test. $\mathrm{CoFeOH} / \mathrm{Ni}$-foam lost $50 \mathrm{mV}$ during the first $25 \mathrm{~h}$

5 The GSS test of the Ni-foam electrode was abandoned after $82 \mathrm{~h}$ due to technical reasons. 
of the test, followed by activation at a rate of $0.13 \mathrm{mV} \mathrm{h}^{-1}$ during the next $100 \mathrm{~h}$, after that the overpotential value remained stable at $1.64 \pm 0.045 \mathrm{~V}$. After short conditioning during the first three GSS test cycles the $\mathrm{CoFeOH} / \mathrm{Ni}$-foam str underwent slow degradation at a rate of $0.375 \mathrm{mV} \mathrm{h}^{-1}$ during the first $140 \mathrm{~h}$ and then at $0.086 \mathrm{mV} \mathrm{h}^{-1}$ until the end of the test. The potential of Ni-foam str, CoFeOH/Nifoam and $\mathrm{CoFeOH} / \mathrm{Ni}$-foam str after $320 \mathrm{~h}$ was $1.73,1.66$ and $1.60 \mathrm{~V}$, respectively. Figure 6d shows a SEM image of $\mathrm{CoFeOH} / \mathrm{Ni}$-foam str after the GSS test. In contrast to the freshly prepared electrode, the $\mathrm{CoFeOH} / \mathrm{Ni}$-foam str electrode after the GSS test was covered with small spherical particles. EDX mapping did not reveal any difference in Fe or Co content in these particles compared to the rest of the coating.

\section{Conclusions}

The electrochemical deposition of cobalt-iron double hydroxide $(\mathrm{CoFe}-\mathrm{OH})$ on nickel foam to form a highly active and durable electrode for oxygen evolution was demonstrated. The influence of the composition, thickness and morphology of the $\mathrm{CoFe}-\mathrm{OH}$ films were thoroughly investigated in order to optimize the OER performance and stability of the electrode. It was demonstrated that the film composition does not only depend on the precursor electrolyte composition, but also on the deposition procedure. Maximum activity was reached for films with 10-30 at.\% Fe content. In situ Raman spectroscopy of the $\mathrm{Co}_{0.7} \mathrm{Fe}_{0.3} \mathrm{OH}_{\mathrm{x}}$ film revealed reversible structure change during $\mathrm{Co}^{2+} / \mathrm{Co}^{3+}$ oxidation/reduction, while there was no further change of the catalyst structure at OER conditions. The optimized deposition procedure was applied for preparation of $\mathrm{CoFe}-\mathrm{OH} / \mathrm{Ni}$-foam electrodes, and long-term performance was demonstrated at a high industrial scale current density of $400 \mathrm{~mA} \mathrm{~cm}^{-2}$.

Acknowledgements: The authors are grateful to the DFG in the framework of the SPP1613 (SCHU929/12-1 and 12-2) and to the Bundesministerium für Bildung und Forschung (BMBF) in the framework of the project "Mangan" (FKZ 03EK3548). Dr. Fengkai Yang is acknowledged for the XRD measurements.

\section{References}

1. T. R. Cook, D. K. Dogutan, S. Y. Reece, Y. Surendranath, T. S. Teets, D. G. Nocera, Chem. Rev. 110 (2010) 6474.

2. N. S. Lewis, D. G. Nocera, Proc. Natl. Acad. Sci. U.S.A. 103 (2006) 15729. 
3. I. C. Man, H.-Y. Su, F. Calle-Vallejo, H. A. Hansen, J. I. Martínez, N. G. Inoglu, J. Kitchin, T. F. Jaramillo, J. K. Nørskov, J. Rossmeisl, ChemCatChem 3 (2011) 1159.

4. H. Qiu, L. Zeng, T. Lan, X. Ding, M. Wei, J. Mater. Chem. A 3 (2015) 1619.

5. R. Gutkowski, D. Schäfer, T. C. Nagaiah, J. E. Y. Heras, W. Busser, M. Muhler, W. Schuhmann, Electroanalysis 27 (2015) 285.

6. N. Weidler, S. Paulus, J. Schuch, J. Klett, S. Hoch, P. Stenner, A. Maljusch, J. Brötz, C. Wittich, B. Kaiser, W. Jaegermann, Phys. Chem. Chem. Phys. 18 (2016) 10708.

7. T. Mikolajczyk, M. Turemko, B. Pierozynski, J. Electroanal. Chem. 735 (2014) 32.

8. H. Maki, M. Takigawa, M. Mizuhata, ACS Appl. Mater. Interfaces 7 (2015) 17188.

9. X. Lu, C. Zhao, Nat. Commun. 6 (2015) 6616.

10. M. S. Burke, L. J. Enman, A. S. Batchellor, S. Zou, S. W. Boettcher, Chem. Mater. 27 (2015) 7549.

11. G. H. A. Therese, P. V. Kamath, Chem. Mater. 12 (2000) 1195.

12. Y. Zhan, G. Du, S. Yang, C. Xu, M. Lu, Z. Liu, J. Y. Lee, ACS Appl. Mater. Interfaces 7 (2015) 12930.

13. P. F. Liu, S. Yang, L. R. Zheng, B. Zhang, H. G. Yang, J. Mater. Chem. A 4 (2016) 9578.

14. L.-A. Stern, X. Hu, Faraday Disc. 176 (2014) 363.

15. S. Zou, M. S. Burke, M. G. Kast, J. Fan, N. Danilovic, S. W. Boettcher, Chem. Mater. 27 (2015) 8011.

16. F. Lyu, Q. Wang, S. M. Choi, Y. Yin, Small 15 (2019) 1804201.

17. M. Gong, Y. Li, H. Wang, Y. Liang, J. Z. Wu, J. Zhou, J. Wang, T. Regier, F. Wei, H. Dai, J. Am. Chem. Soc. 135 (2013) 8452.

18. Y. Vlamidis, E. Scavetta, M. Gazzano, D. Tonelli, Electrochim. Acta 188 (2016) 653.

19. M. S. Burke, M. G. Kast, L. Trotochaud, A. M. Smith, S. W. Boettcher, J. Am. Chem. Soc. 137 (2015) 3638.

20. S. J. Kim, Y. Lee, D. K. Lee, J. W. Lee, J. K. Kang, J. Mater. Chem. A 2 (2014) 4136.

21. D. Friebel, M. W. Louie, M. Bajdich, K. E. Sanwald, Y. Cai, A. M. Wise, M.-J. Cheng, D. Sokaras, T.-C. Weng, R. Alonso-Mori, R. C. Davis, J. R. Bargar, J. K. Nørskov, A. Nilsson, A. T. Bell, J. Am. Chem. Soc. 137 (2015) 1305.

22. C. G. Morales-Guio, L. Liardet, X. Hu, J. Am. Chem. Soc. 138 (2016) 8946.

23. F. Yang, K. Sliozberg, I. Sinev, H. Antoni, A. Bähr, K. Ollegott, W. Xia, J. Masa, W. Grünert, B. R. Cuenya, W. Schuhmann, M. Muhler, ChemSusChem 10 (2017) 156.

24. L. A. Bromley, AIChE J. 19 (1973) 313.

25. R. A. Nickell, W. H. Zhu, R. U. Payne, D. R. Cahela, B. J. Tatarchuk, J. Power Sources 161 (2006) 1217.

26. X. H. Xia, J. P. Tu, Y. Q. Zhang, Y. J. Mai, X. L. Wang, C. D. Gu, X. B. Zhao, J. Phys. Chem. C 115 (2011) 22662.

27. A. Maljusch, O. Conradi, S. Hoch, M. Blug, W. Schuhmann, Anal. Chem 88 (2016) 7597.

28. J. R. S. Brownson, C. Lévy-Clément, Phys. Stat. Sol. (b) 245 (2008) 1785.

29. J. O.' M. Bockris, J. Chem. Phys. 24 (1956) 817.

30. J. O.' M. Bockris, T. Otagawa, J. Phys. Chem. 87 (1983) 2960.

31. T. Shinagawa, A. T. Garcia-Esparza, K. Takanabe, Sci. Rep. 5 (2015) 13801.

32. J.-X. Feng, H. Xu, Y.-T. Dong, S.-H. Ye, Y.-X. Tong, G.-R. Li, Angew. Chem. Int. Ed. 55 (2016) 3694.

33. H. Jin, S. Mao, G. Zhan, F. Xu, X. Bao, Y. Wang, J. Mater. Chem. A 5 (2017) 1078.

34. Y.-H. Fang, Z.-P. Liu, ACS Catal. 4 (2014) 4364.

35. J. Yang, H. Liu, W. N. Martens, R. L. Frost, J. Phys. Chem. C 114 (2010) 111. 
36. C.-W. Tang, C.-B. Wang, S.-H. Chien, Thermochim. Acta 473 (2008) 68.

37. G.-H. Moon, M. Yu, C. K. Chan, H. Tüysüz, Angew. Chem. Int. Ed. 58 (2019) 3491.

38. B. S. Yeo, A. T. Bell, J. Am. Chem. Soc. 133 (2011) 5587.

39. L. J. Enman, M. S. Burke, A. S. Batchellor, S. W. Boettcher, ACS Catal. 6 (2016) 2416.

40. S.-H. Ye, Z.-X. Shi, J.-X. Feng, Y.-X. Tong, G.-R. Li, Angew. Chem. Int. Ed. 57 (2018) 2672.

41. F. Lyu, Y. Bai, Q. Wang, L. Wang, X. Zhang, Y. Yin, Mater. Today Chem. 11 (2019) 112.

42. M. W. Louie, A. T. Bell, J. Am. Chem. Soc. 135 (2013) 12329. 